\title{
The Students' Behavior Self-evaluation Scale in a Greek Multicultural Educational Frame
}

\author{
${ }^{1}$ Filippos Filippou*, ${ }^{1}$ Stella Rokka, ${ }^{1}$ Olga Kouli, ${ }^{1}$ Aikaterini Koupani, ${ }^{1}$ Grigorios \\ Masadis, ${ }^{1}$ Evangelos Bebetsos, ${ }^{1}$ Vasiliki Derri, ${ }^{1}$ Stella Kagianni \\ ${ }^{1}$ Department of Physical Education and Sport Science, Democritus University of Thrace, Komotini, Greece.
}

Submitted 22 May 2019; Accepted in final form 01 August 2019.

\begin{abstract}
Background. The subject of PE is often considered as a field of equal opportunities and cultural coexistence, which facilitate social skills and create a harmonic environment. Sports are a most suitable field for developing social skills, facing the "different" and embodying normally all the participants who come from different cultural environments. Objectives. The aim of this study was to control the validity and credibility of the Greek version Student's Behaviors'Self-evaluation Scale, in a Greek multicultural educational environment and specifically in relation to secondary school students during their participating in the physical education classes. The psychometrical qualities of the scale were examined in addition to the influence of gender and age, as factors which differentiate the social skills of students. Methods. The participants of the research were 182 male and female students studying in six multicultural secondary Schools in distinct geographical areas. The statistical analyses that were applied were: Confirmatory factor analysis, Reliability analysis, Independent-sample t-test and one-way ANOVA analysis. Results. The results showed that the internal consistency of the sub-scales was high, since $\alpha$ Cronbach fluctuated in high levels (goals 0.84 , rewards 0.85 , relations 0.88 , irresponsibility 0.78 and help 0.79 ). The confirmatory factor analysis certified the suggested structure of the climax $\left(\chi^{2}(413.33) /\right.$ d.f. $(109)=3.79 ; \mathrm{P}<0.05 ; \mathrm{NFI}=0.91, \mathrm{CFI}=0.92$, RMSEA=0.075 and $\mathrm{SRMR}=0.042$ ). Conclusion. Therefore, the results confirmed the suitability of the Students' Behavior Self-evaluation Scale for the Greek school environment during physical education lesson. In addition, there was a confirmation that gender is a differentiation factor, while class (age) is not.
\end{abstract}

KEYWORDS: Student's Behaviors' Self-evaluation Scale, Multicultural School Environment, Physical Education and Training, Students of Secondary School

\section{INTRODUCTION}

Throughout the centuries, all kinds of societies have developed institutions through which they transmitted their knowledge, values and structures to the next generations, the way they were shaped by the communal environment (1). Social skills were part of the communal values through which, in addition to other merits, the community succeeded its unity and uninterrupted evolution (2). In modern societies, the role of the old communal institutions is played by the family and school environment. Particularly today, in an environment of fast and deeply changing values and economic conditions, the Greek school must teach its students skill such as elaboration of information, ability to communicate and ability to adapt to different educational and work environments, in order to embody and evolve successfully in modern society (3). According to Danish and Nellen, these skills are called life skills, since they help a person distinguish in the

*. Corresponding Author:

Filippos Filippou, Associate Professor

E-mail: ffilippo@phyed.duth.gr 
society he/she lives. Part of such life skills are social skills, which are indispensable for communicating, verbally or not, within small or larger groups (4).

It has been supported that a person acquires social skills when he/she demonstrates a socially acceptable behavior, interacts with others effectively and avoids negative, anti-social behaviors (5). According to Riggio, all basic social behaviors can be learned and evolve into social skills and strategies (6). Cardarella and Merrell support that social skills can be classified in five basic categories: the first category includes "relationships with peers" i.e. acquisition of friends, communication, discussion, supporting and helping friends (7). The second category is "self-control" i.e. following rules, accepting opinions and exercising constructive criticism, as well as cooperating under different conditions. The third category concerns "academic course" i.e. being methodic while studying and completing work procedures. "Discipline" i.e. conforming to directions and rules characterizing a social group is the fourth basic category of social skills and "responsibility" i.e. claiming your rights is the fifth basic category. While family and the broader circle of relatives have always been the initial space for learning social skills (8), school supports and enhances social education (9).

Physical Education (PE) is probably the most important school subject for acquiring social skills, since on the one hand students are constantly in an interactive condition and on the other hand, games -a basic ingredient of the teaching material- have always been a field for learning the social rules of behavior and discipline (10). Children like learning through moving and playing (11), while simultaneously they develop their cooperation, exchange opinions and solve problems of both individual and group nature (12).

The subject of PE is often considered as a field of equal opportunities and racial harmony, which facilitate social skills and create a harmonic environment (13).

Sports are a most suitable field for developing social skills, facing the "different" and embodying normally all the participants who come from different cultural environments (14). The subject of PE, due to its dominant kinesthetic character, has the chance to unite students, cultivate harmonic relationships and inspire respect towards the others, through the global language of movement. Athletic games and dance, being the basic structural elements of PE, create the frame for the embodiment and cooperation of all students despite their cultural origins, age and gender, and can be used as tools in order to approach and accept differences, as well as reduce conflicts and inequalities among students (15).

As concerns age and gender, recent researches have shown that the older the students get, especially during their transitional period from Primary to Secondary School, the more their social skills are reduced while they become antisocial in both their lives and the PE classes (16). In relation to gender, there are significant differences in social skills among male and female students, while studying in Primary and Secondary School. According to studies, the evaluations of the females' social skills were considerably more positive than those of males (17). Female students' present more positive behaviors in both their social environment (18, 19) and PE classes (20) and greater tolerance towards foreign students (21), while according to other studies, there were not significant differences between male and female students concerning verbal bullying and exclusion (22). Thus, a constant evaluation of all students' social skills and the extent to which they are influenced by age, gender or nationality is significant. All the above arguments can justify the reason why the existence of an instrument measuring the social skills of students is of utmost importance for a teacher. Thus, the aim of this research was to confirm the validity and credibility of Student's Behaviors' Self-evaluation Scale by Kagianni, Filippou, Bebetsos, Rokka, and Masadis (23). The parameters examined were the psychometric qualities of the scale and the influences of gender and age, as factors which differentiate students' behavior.

\section{MATERIALS AND METHODS}

Participants. The participants of the research were male and female students (182) coming from six secondary schools, in different geographical areas of Greece. The schools were chosen after drawing a lottery, while taking into consideration their location ( 2 were in rural areas, 2 were in semi-urban areas and 2 were in urban areas) and the number of the counties represented. More specifically, 300 questionnaires were sent to students of all three classes of secondary 
schools in rural, semi-urban and urban areas. The questionnaires that were sent back were 225 i.e. $73.33 \%$ of the original number sent. After checking the correct completion of the questionnaires, 182 of them were found to be legitimate for participating, that is $82.73 \%$ of the questionnaires were completed correctly (Table 1). The composition of the sample was international. In addition to Greek students, there were also Albanian, Bulgarian and Georgian students as well as a percentage of Roma students.

\begin{tabular}{|c|c|c|c|c|c|c|}
\hline \multirow{2}{*}{$\begin{array}{c}\text { Class } \\
\text { attendance } \\
\text { 1rst (13 years } \\
\text { old) }\end{array}$} & \multicolumn{2}{|c|}{ Male } & \multicolumn{2}{|c|}{ Female } & \multicolumn{2}{|c|}{ Total } \\
\hline & 35 & $19.23 \%$ & 36 & $19.78 \%$ & 71 & $39.01 \%$ \\
\hline $\begin{array}{l}\text { 2nd (14 years } \\
\text { old) }\end{array}$ & 28 & $15.38 \%$ & 37 & $20.33 \%$ & 65 & $35.71 \%$ \\
\hline $\begin{array}{l}\text { 3rth (15 years } \\
\text { old) }\end{array}$ & 24 & $13.19 \%$ & 22 & $12.09 \%$ & 46 & $25.28 \%$ \\
\hline Total & 87 & $47.80 \%$ & 95 & $52.20 \%$ & 182 & $100.00 \%$ \\
\hline
\end{tabular}

Measurements. The Greek version (23) of the Student's Behaviors' Self-evaluation Scale (SBSS) by Kellis, Vernadakis, Albanidis, Derri and Kourtesses (24) was used in the present research because it is brief and easy to use and it does not hinder students' concentration while completing the questionnaire. It is made for students attending multi-cultural schools and the skills are evaluated by the students themselves. Tirri (25) considers self-evaluation more credible than that of a teacher or anyone else since, according to Gardner (26) selfevaluation is a starting point in the process of acquiring new information.

The scale by Kellis, Vernadakis, Albanidis, Derri and Kourtesses (24) includes 18 statements/questions which are classified in 5 dimensions/factors: the first factor "relations" consists of three questions (e.g. "I like making friends through dancing"). The second factor "irresponsibility" consists of three questions (e.g. "during dance classes I address others in an insulting way about their origin"). The third factor "rewards" consists of four questions (e.g. I applaud those who do well during dance classes"). The fourth factor "help" consists of four questions (e.g. I accept other students' help when I cannot cope in dance classes"). The fifth factor "goals" consists of four questions (e.g. "I set individual goals in order to improve in dance classes").

While being constructed, the questionnaire displayed a good constructive validity, since its five factors explained $72.09 \%$ of the total fluctuation and the internal cohesion of the five factors was satisfactory because Cronbach $\alpha$ ranged between 0.79 for the factor "help" to 0.88 for the factor "relations" (16).

The Greek version of the questionnaire includes 17 questions, although the questionnaire used did not include the question "I pay attention to other students" safety during dance classes", since there were not any safety problems observed. The answers were given on a 5 degree Likert scale from $1=$ totally disagree, $2=$ disagree, $3=\mathrm{I}$ am not sure, $4=$ agree and $5=$ totally agree (appendix 1).

The translation and adaptation of the questionnaire for the Greek population was carried out taking into consideration the methodology (back to back translation) proposed by Banville, Desroriers and GenetVolet (26).

Procedure. The students' parents were asked to give their written permission for the participation of their children after being informed on the targets of the research and were given confirmation that the results will be used for exclusively educational/scientific reasons.

Statistical Analysis. For the statistical analysis of the data the methods used were: Confirmatory factor analysis (CFA), Reliability analysis, Descriptive analysis, Independent t-test for independent samples and one-way ANOVA analysis.

\section{RESULTS}

Confirmatory Factor Analysis. A confirmatory factor analysis was carried out with the use of the statistical packet LISREL 8.80 on the five factors of the SBSS. The hypothetical/suggested model consists of five factors the first of which is called «relations», the second «irresponsibility», the third «rewards», the fourth «help» and the fifth «goals». 
The credibility/normal adjustment indicators that were examined are: namely minimum discrepancy/CMIN or $\chi^{2}$, degrees of freedom/d.f., Root Mean Square Error of Approximation (RMSEA), Standardized Root Mean Square Residual (SRMR), Comparative Fit Index, /CFI and Normed Fit Index (NFI) (27-29). All the above indicators are presented in Table 2. The model presents normal adjustment when the indicators have the following prices: $\chi^{2} /$ d.f. is $<0.5(30)$, CFI and
NFI are $>0.90$ (31), RMSEA is $<0.08$ (32) SRMR is $<0.05$ (33). The statistical control of the results of this research showed that the hypothetical model presented a considerable $\chi^{2}$ $(413.33) /$ d.f. $(109)=3.79, \quad \mathrm{P}<0.05$. The indicators NFI and CFI were found satisfactory with prices 0.91 and 0.92 respectively. The prices of RMSEA and SRMR also confirm the normal adjustment of the model, since RMSEA was found with 0.075 and SRMR with 0.042 (Table 2).

Table 2. Credibility/Normal Adjustment of SBSS

\begin{tabular}{|ccccccccc|}
\hline \multicolumn{10}{|c}{ T } & $\mathbf{X}^{\mathbf{2}}$ & $\mathbf{D F}$ & $\mathbf{X}^{2} / \mathbf{D F}$ & $\mathbf{N F I}$ & $\mathbf{C F I}$ & RMSEA & SRMR \\
Model & 182 & 413.33 & 109 & 3.79 & 0.91 & 0.92 & 0.075 & 0.042 \\
\hline
\end{tabular}

The five factors explained $72.09 \%$ of the total variance. The factor "relationships" explained $6.85 \%$ of the total variance; the factor «irresponsibility» $8.70 \%$ of the total variance; the factor "rewards" $31.49 \%$; the factor "help" $10.65 \%$ and the factor "goals" explained $14.40 \%$ of the total variance. The internal consistency of Cronbach's alpha coefficients were: 0.84 for the factor "goals" (four items), 0.85 for the factor "rewards", (four items), 0.88 for the factor "relations" (three items), 0.78 for the factor "irresponsibility" (three items) and 0.79 for the fifth factor "help" (three items). Cronbach's alpha means and standard deviation are presented in Table 3.

Table 3. Means - Standard Deviation and Internal Consistency

\begin{tabular}{|lccc|}
\multicolumn{4}{c}{ for each Factor } \\
\hline Factors & M. & S.D. & Cronbach a \\
Goals & 3.54 & 0.57 & 0.84 \\
Rewards & 2.74 & 0.77 & 0.85 \\
Relations & 3.77 & 0.81 & 0.88 \\
Irresponsibility & 2.28 & 0.76 & 0.78 \\
Help & 3.54 & 0.62 & 0.79 \\
\hline
\end{tabular}

Differences in Social Skills in Relation to Gender. The Independent-sample t test analysis was applied to check whether there were any statistically significant differences in the questionnaire factors between boys and girls. The results showed that there were statistically significant differences only in the factor "goals" $\left[\mathrm{t}_{(180)}=4.51 ; \mathrm{P}<0.05\right]$ and in the factor "relationships" $[\mathrm{t} \quad(180)=3.85 ; \mathrm{p}<0.05]$. Specifically, as for the factor "goals" female students presented significantly higher value (M. $=3.77 \&$ S.D. $=0.68)$ in relation to male students (M. $=3.34 \&$ S.D. $=0.61$ ) and in the factor "relationships" the female students stated statistically significant higher means (M. $=3.96 \&$
S.D. $=0.85)$ in relation to male students $(M .=3.60$ $\&$ S.D. $=0.93$ ).

Differences in Social Skills in Relation to Classes' Attendance. In order to determine whether there were statistically significant differences in the social skills of students' in relation to class attendance, the one-way ANOVA analyses were conducted. The results showed that there were not statistically significant differences due to the "attendance class" for the factor «goals» $\left[\mathrm{F}_{(2,179)}=.224, \mathrm{P}>0.05\right] ;$ «rewards» $\left[\mathrm{F}_{(2,179)}=1.52, \mathrm{P}>0.05\right] ;$ 《relationships» $\left[\mathrm{F}_{(2,179)}\right.$ $=1.82, \mathrm{P}>0.05]$; «irresponsibility» $\left[\mathrm{F}_{(2,179)}=.424\right.$, $\mathrm{P}>0.05]$ and $\ll$ help» $\left[\mathrm{F}_{(2,179)}=1.90, \mathrm{P}>0.05\right]$.

\section{DISCUSSION}

The aim of the present study was to evaluate the validity and credibility of Students' Behavior Self-evaluation Scale $(23,24)$ adjusted to the Greek environment and specifically for the Secondary School students while participating in traditional dances during PE classes and the way it is differentiated by gender and age.

The results of the present research, concerning the structural validity of both the climax in general and its partial factors showed that the specific sample presented a five factor structure which agreed with the findings of its creators (23). Thus, the five factors «relations», «irresponsibility», «rewards», «help» and «goals» which were suggested by the creators were confirmed in the present research and they all interpreted $72.09 \%$ of the total fluctuation. Similarly, the results concerning the internal cohesion of both the climax in general and every factor separately were very high. It must be mentioned here that the Greek version of the climax excluded the sentence «I pay attention to the safety of others then I participate in dance 
activities», since traditional dance classes, to which the questionnaires were addressed, are considered to be safe enough. Consequently, the factor «help» consists of three sentences instead of the four suggested by the creators of the climax.

As concerns the degree of the social skills of the secondary school students who were examined in the present study, the results showed that the sample did not present a high degree of anti-social skills, since the five factors of the climax had quite satisfactory means, with the highest ones being «relations» $($ mean=3.77) and «help» (mean $=3.54 »$. It seems that the students developed good relationships among them and, simultaneously, they were eager to give help to their fellow students when necessary i.e. they were ready to offer and accept knowledge and skills, in order to support and ameliorate the class level. This is also confirmed by the results of the factor «irresponsibility» which presented the lowest mean (2.28) and which shows that the students acknowledge and respect other people's personality.

The results of the research are in agreement with those of Derri, Kellis, Vernadakis, Albanidis and Kioumourtzoglou, who supported that the subject of Physical Education -through movement, dance and team games- can promote and enhance personal and social responsibility in all students and encourage the development of social skills, so as to help them coexist effectively in various frames (34). In the findings of their research, the factor «help» presented the lowest mean nevertheless their research was carried out with a sample of 79 Elementary School students of the $5^{\text {th }}$ and $6^{\text {th }}$ grade, while in the present research, which implicated secondary school students, the same factor presented the highest mean.

Concerning the examination of the differences between boys and girls i.e. whether gender can be a differentiation factor for social skills, it was found that female students had higher goals than male students and they seemed more determined to acknowledge their fellow students and create relationships with them. Likewise, a research by Malinauskas and Emeljanovas (35) concerning the level of 13-14 year old students' social skills during Physical Education classes and the differences between the two genders in secondary schools found that female students presented higher levels of social skills.
In addition, the results of the present study showed that class and age are not factors which differentiate social skills, since there were no statistically significant differences in the means for any of the factors of the scale. The results of this research oppose those of Masadis (36) whose research showed that students of the $4^{\text {th }}$ grade of primary school had less developed social skills than those of the $5^{\text {th }}$ and $6^{\text {th }}$ grades. The researchers attributed this differentiation to the fact that $4^{\text {th }}$ grade students were not taught how to coexist with others effectively, due to the limited time of education. Nonetheless, the results of the present study, which included students from all three grades of secondary school, showed that class/age did not present any differences, given the fact that there was enough time for education.

Eldar and Ayvazo (11) supported that social skills are necessary for a successful performance at school and in life. Furthermore, Bielecki and Swender (37) defined social skills as observable and measurable interpersonal relationships which promote independence and acceptance of individuality by the group while they provide people with the ability to avoid interpersonal conflicts, cope with stressful conditions, acquire healthy relationships and adapt to the demands of society as individuals. On the other hand, a number of researches show that insufficient social skills are connected with various problems including aggressive and anti-social behaviors, even to the extent of causing social isolation (38).

School environment and especially secondary school is a critical threshold in the life of male and female students and defines the development of their social lives and their academic evolution. Considering the changes caused by adolescence and also the social/economic situation of Greece, secondary school years are essential for the development of students in their adult lives. Given the circumstances, the subject of PE plays an important role, as it suggests models of social behavior and diminishes anti-social perceptions (aggressiveness, denial of the different). According to Tjeerdsma (39), the subject of PE is the utmost space for developing the social and emotional skills of youths and its environment can be used to improve social skills, values and good characters. Thus, the climate created during a PE lesson -a subject most popular among students- is suitable for developing social skills (40), since students communicate directly with one another and the activities enacted (games, 
dance, team sports) create emotional interactions such as cooperation, team spirit, self-discipline, responsibility, courage, self-respect and admiration for the rival as well as honesty and justice.

The role of the PE teacher is significant, since his/her subject is among those which can teach students social skills successfully. Therefore, there is need for a credible instrument that the teacher could use to help students develop social skills and render the lesson effective. The results of the present study, concerning the control of the structural validity of the Students' Behaviors Self-evaluation Scale by Kellis et al. (24) showed that the specific scale is a valid and credible instrument for evaluating the social skills of secondary school students, who study in a multicultural environment. Self-evaluation through the Students' Behaviors Self-evaluation Scale -a process during which a person evaluates his/her efforts in order to improve or alter them- is a necessary, valid and credible measurement instrument that develops self-knowledge and social responsibility. The use of the specific scale which is used for self-evaluating social skills is expected to improve students' behaviour, cooperation, acceptance of the different, acquisition of trust of the others and to finally create responsible persons.

\section{CONCLUSION}

In today's Greece, a country which receives more and more emigrants, the creation of a school environment that will be able to handle cultural differences and develop those conditions that will promote a harmonic coexistence among students in the frame of educational procedure is of crucial importance. Schools should promote an environment which will produce students who are able to adapt to the constantly changing social demands and prepare for their role as active citizens in a global society. In order that schools remain a creative institution and manage to follow the rhythm of society, they should equip students with the necessary social skills so that they manage to live effectively and successfully in their environment.

The present research concerned male and female students from Greece or abroad studying in multi-cultural High Schools. Therefore, a wider research is suggested to include conventional Junior and Senior High Schools.

\section{APPLICABLE REMARKS}

- The Students' Behavior Selfevaluation Scale has appropriate validity and reliability as well as high sensitivity and is suitable in a multicultural education context during Physical Education's lesson.

- The Physical Education's teachers can use the SBSS to evaluate the social skills of their students.

\section{REFERENCES}

1. Dimas I. The transformation of cultural creation: from traditional society to the modern industrial world. In: Avdikos E, editor. Choreftika Eteroklita: Greek Letters; 2004. p. 291-296.

2. Avdikos E. Feast and dance groups: experience and revival of tradition. In: Avdikos E, editor. Choreftika Eteroklita: Greek Letters; 2004. p. 203-212.

3. Papaioannou A, Y T, Goudas M. For a better physical education. Thessaloniki: Christodoulidis; 2003.

4. Danish SJ, Nellen VC. New Roles for Sport Psychologists: Teaching Life Skills Through Sport to AtRisk Youth. Quest. 1997;49(1):100-113. doi: 10.1080/00336297.1997.10484226

5. Gresham FM, Elliott SN. Social skills rating system: Manual: American Guidance Service; 1990.

6. Riggio RE. Assessment of basic social skills. J Pers Soc Psychol. 1986;51(3):649-660. doi: 10.1037/0022-3514.51.3.649

7. Caldarella P, Merrell KW. Common dimensions of social skills of children and adolescents: A taxonomy of positive behaviors. Sch Psychol Rev. 1997;26(2):264-278.

8. Simons RL, Whitbeck LB, Conger RD, Conger KJ. Parenting factors, social skills, and value commitments as precursors to school failure, involvement with deviant peers, and delinquent behavior. $J$ Youth Adolesc. 1991;20(6):645-664. doi: 10.1007/BF01537367 pmid: 24263616

9. Segrin C, Hanzal A, Donnerstein C, Taylor M, Domschke TJ. Social skills, psychological well-being, and the mediating role of perceived stress. Anxiety Stress Coping. 2007;20(3):321-329. doi: 10.1080/10615800701282252 pmid: 17999232 
10. Biddle S, Wang CKJ, Kavussanu M, Spray C. Correlates of achievement goal orientations in physical activity: A systematic review of research. Eur J Sport Sci 2003;3(5):1-20. doi: 10.1080/17461390300073504

11. Eitan E, Shiri A. Educating Through the Physical - Rationale. Educ Treat Children. 2009;32(3):471486. doi: $10.1353 /$ etc. 0.0061

12. Gregoriadis A, Grammatikopoulos V, Zachopoulou E. Evaluating preschoolers' social skills: The impact of a physical education program from the parents' perspectives. Int J Hum Soc Sci. 2013;3(10):40-51.

13. Parry J. Physical Education as Olympic Education. Eur Phys Educ Rev. 2016;4(2):153-167. doi: 10.1177/1356336x9800400206

14. Morela E, Hatzigeorgiadis A, Kouli O, Elbe A-M, Sanchez X. Team cohesion and ethnic-cultural identity in adolescent migrant athletes. Int $J$ Intercult Relat. 2013;37(5):643-647. doi: 10.1016/j.ijintrel.2013.05.001

15. Vorwald M. Best practises. Integrating Multicultural Games \& Activities into your PE Curriculum: UWSP; $2012 . \quad$ Available from: http://www.uwsp.edu/conted/ConfWrkShp/Documents/bestpractice/handouts/Vorwald.pdf.

16. Papageorgiou M, Hassandra M, Hatzigeorgiadis A. Fair Play in Physical Education: Effects of Sex, Age and Intrinsic Motivation. Inq Sport Phys Educ. 2008;6(2):162-168.

17. Margetts K. Children's adjustment to the first year of schooling: indicators of hyperactivity, internalizing and externalizing behaviors. Int J Transit Childhood. 2005;1:36-44.

18. Giavrimis P, Papanis E. [Assessment of social competence and Antisocial behavior of school age children] 2007 [cited 2018]. Available from: http://epapanis.blogspot.com/2007/09/ph.html.

19. Jurado M, Cumba-Avilés E, Collazo LC, Matos M. Reliability and Validity of a Spanish Version of the Social Skills Rating System-Teacher Form. J Psychoeduc Assess. 2016;24(3):195-209. doi: 10.1177/0734282906288961

20. Hassandra M, Goudas M, Theodorakis Y, editors. Variation and relations of fair play behavior, fair play atmosphere and daily morality of physical education students. 12th European Congress of Sport Psychology; 2007; Halkidiki, Greece.

21. UNICEF. Discrimination-Racism-Xenophobia in the Hellenic educational system: KAPA Research; 2001 [cited 2018]. Available from: http://www.unicef. gr/reports /racism. Php.

22. Wong DSW, Lok DPP, Wing Lo T, Ma SK. School Bullying Among Hong Kong Chinese Primary Schoolchildren. Youth Soc. 2007;40(1):35-54. doi: 10.1177/0044118x07310134

23. Kagianni S, Filippou F, Bebetsos E, Rokka S, Masadis G. Factorial structure and credibility the Self Evaluation Scale of Social Skills in a Multicultural Educational Environment. 15th Panhellenic Congress of Athletic Psychology with International participation «Exercise - Sports \& Psychology: Two Sciences in a dynamic relationship»; Athens2018. p. 98-100.

24. Kellis I, Vernadakis N, Albanidis E, Derri V, Kourtesses T. The development of a students behaviors self-evaluation scale (SBSS) in multicultural physical education class settings. Educ Res Rev. 2010;5(11):637645 .

25. Tirri K, Nokelainen P. Multiple Intelligences Profiling Questionnaire. Measuring Multiple Intelligences and Moral Sensitivities in Education: Sense Publishers; 2011. p. 1-13.

26. Banville D, Desrosiers P, Genet-Volet Y. Translating Questionnaires and Inventories Using a CrossCultural Translation Technique. J Teach Phys Educ. 2000;19(3):374-387. doi: 10.1123/jtpe.19.3.374

27. Mulaik SA, James LR, Van Alstine J, Bennett N, Lind S, Stilwell CD. Evaluation of goodness-of-fit indices for structural equation models. Psychol Bull. 1989;105(3):430-445. doi: 10.1037/0033-2909.105.3.430

28. Bentler PM. Comparative fit indexes in structural models. Psychol Bull. 1990;107(2):238-246. pmid: 2320703

29. McDonald RP, Marsh HW. Choosing a multivariate model: Noncentrality and goodness of fit. Psychol Bull. 1990;107(2):247-255. doi: 10.1037/0033-2909.107.2.247

30. Bentler PM. EQS structural equations program manual. Los Angeles: BMDP Statistical Software; 1989.

31. Hu L, Bentler P. Evaluating model fit. In R. Hoyle (Ed.), Structural equation modelling: Issues, concepts, and applications. Newbury Park, CA: Sage; 1995.

32. Browne M, Cudeck R. Alternative ways of assessing model fit. In: Bollen K, editor. Testing structural equation models. Newbury Park, CA: Sage; 1993. p. 136-162. 
33. Hu Lt, Bentler PM. Cutoff criteria for fit indexes in covariance structure analysis: Conventional criteria versus new alternatives. Struct Equat Mod A Multidiscipl J. 1999;6(1):1-55. doi: 10.1080/10705519909540118

34. Derri V, Kellis I, Vernadakis N, Albanidis E, Kioumourtzoglou E. The effect of an intercultural Physical Education Program in comparison to the typical one on students' social skills learning. J Hum Sport Exerc. 2014;9(1):91-102. doi: 10.4100/jhse.2014.91.10

35. Malinauskas R, Emeljanovas A. Specificity of schoolchildren's social skills during physical education classes. Croat J Educ. 2013;15(Sp. Ed. 4):51-68.

36. Masadis G. Development of Social Skills in 4th, 5th and 6th grade of Primary School Students through the Teaching of Greek Traditional Dances. Komotini, Greece: Democritus University of Thrace; 2017.

37. Bielecki J, Swender SL. The assessment of social functioning in individuals with mental retardation: a review. Behav Modif. 2004;28(5):694-708. doi: 10.1177/0145445503259828 pmid: 15296526

38. Fox RA, Keller KM, Grede PL, Bartosz AM. A mental health clinic for toddlers with developmental delays and behavior problems. Res Dev Disabil. 2007;28(2):119-129. doi: 10.1016/j.ridd.2006.02.001 pmid: 16540284

39. Tjeerdsma B. Physical education as a social and emotional development laboratory. Teach Element Phys Educ. 1999;10(4):12-16.

40. Laker A. The future of physical education: building a new pedagogy. London, UK: Routledge; 2003.

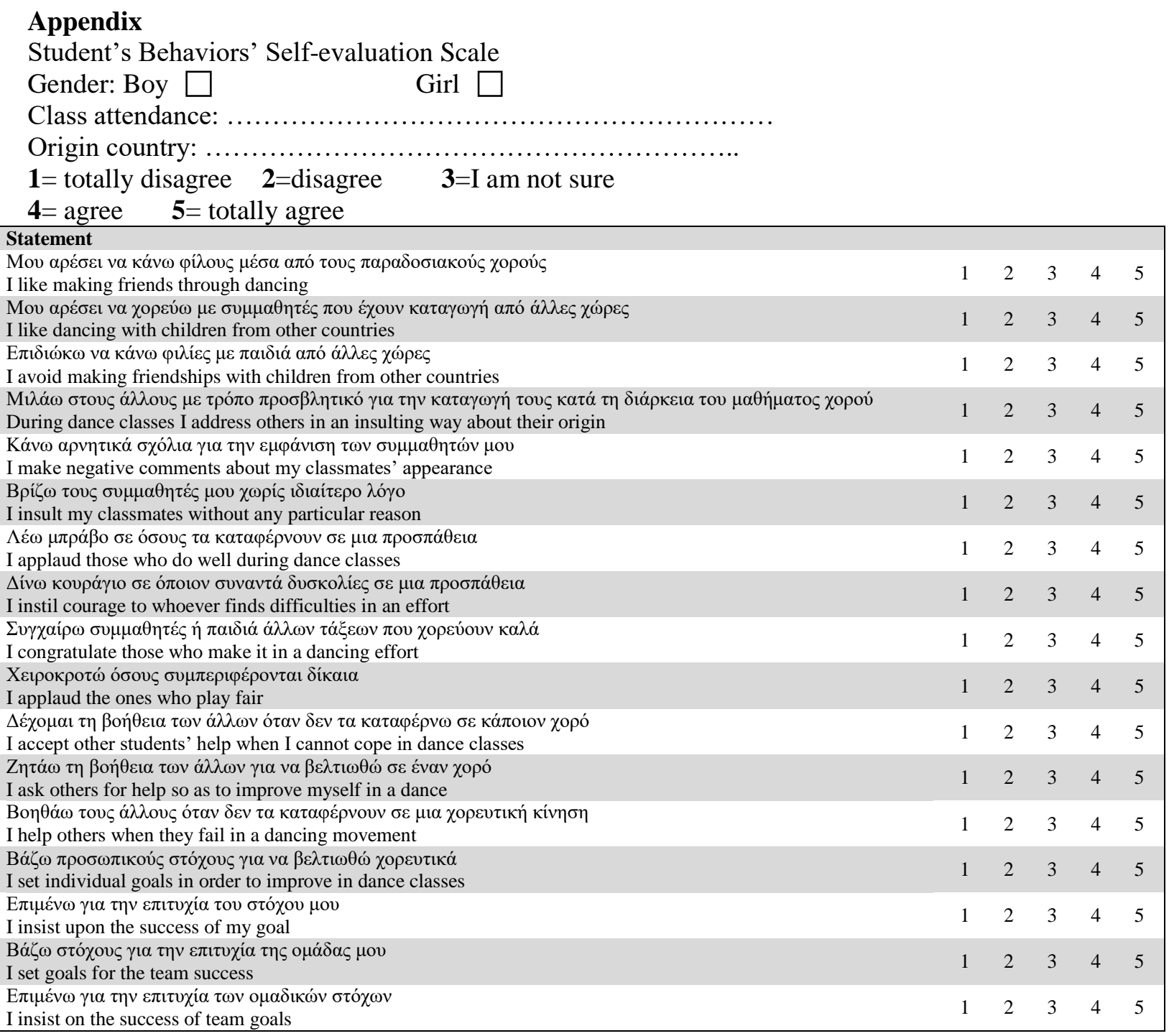

